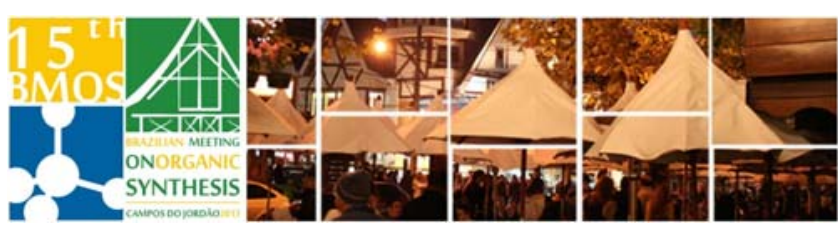

\title{
$\alpha, \beta$-Unsaturated Diazoketones in Aza-Michael Additions - Application in the synthesis of Barmumycin
}

\author{
Rafael Mafra de P. Dias, Antonio C. B. Burtoloso* \\ Instituto de Química de São Carlos, Universidade de São Paulo, CEP 13560-970, São Carlos, SP, Brasil.
}

*e-mail corresponding author: antonio@iqsc.usp.br

Keywords: Diazocompounds, Aza-Michael addition, Barmumycin

\section{INTRODUCTION}

$\alpha, \beta$-unsaturated diazoketones have been proven to be interesting multi-functional building blocks in organic chemistry. ${ }^{1}$ An interesting reaction, little studied with these building blocks is the Aza-Michael reaction. This reaction consists in an important tool for the formation of $\mathrm{C}-\mathrm{N}$ bonds and is extremely useful in the synthesis of natural products. ${ }^{2}$ In this context, we studied the Michael reaction with $\alpha, \beta-$ unsaturated diazoketones and its application in the synthesis of barmumycin (a natural product with antitumor activity).

\section{RESULTS AND DISCUSSION}

Our study started by the investigation of the best conditions for the Michael reaction from diazoketone 1 (figure 1). Although no base was necessary when primary amines were employed, the use of DBU was crucial when secondary amines were used. After this optimization study, several Michael adducts could be prepared in moderate to good yields employing different amines and diazoketones (figure 2).

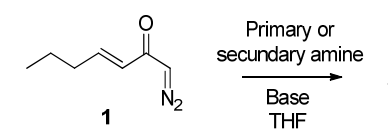

Conditions

1) Allyamine (3eq)

2) Diallyamine (10eq)

3) Diallyamine (10eq), $\mathrm{Et}_{3} \mathrm{~N}(0,5 \mathrm{eq})$

Yield (\%)

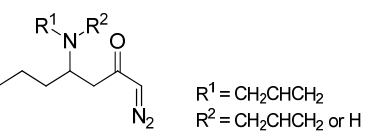

Conditions

4) Diallyamine (10eq), DBU $(0,3 e q)$ 5) Diallyamine (10eq), DBU $(0,5 \mathrm{eq})$ 6) Diallyamine (5eq), DBU $(0,5 \mathrm{eq})$
Yield (\%)

35 37 47
Figure 1. Investigation of the conditions for the Michael reaction

The application of this methodology is now being demonstrated in the synthesis of barmumycin. As depicted in Figure 3, the synthesis started after the Michael reaction of benzylamine with diazoketone 2, to give compound $\mathbf{3}$ in $76 \%$ yield. The next steps involved an intramolecular rhodium catalyzed $\mathrm{N}-\mathrm{H}$ insertion reaction from 3 , followed by the $N$ protecting group exchange. Completion of the synthesis of Barmumycin is under course and involves a selective olefination and TBS group removal.

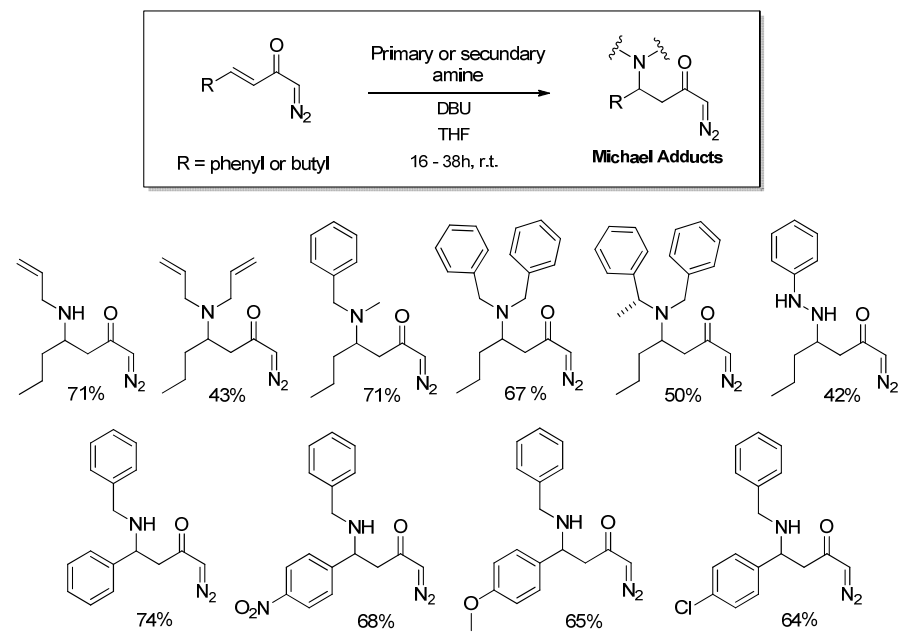

Figure 2. Michael adducts prepared from $\alpha, \beta$-unsaturated diazoketones

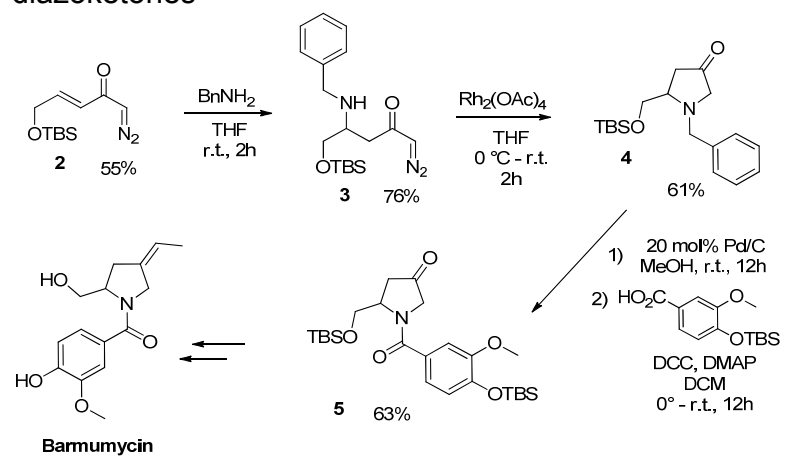

Figure 3. Evaluation of the synthesis of Barmumycin

\section{CONCLUSION}

In summary, it was demonstrated the use of $\alpha, \beta-$ unsaturated diazoketones as good Michael acceptors in the presence of primary and secondary amines. This reaction is being applied in a straightforward synthesis of the alkaloid barmumycin.

\section{ACKNOWLEDGEMENTS}

IQSC - USP, CNPq e Fapesp.

\section{REFERENCES}

${ }_{1}^{1}$ Pinho, V. D.; Burtoloso, A. C. B. J. Org. Chem., 2011, 76, 289.

${ }^{2}$ Rulev, A. Y. Russ. Chem. Rev. 2011, 80, 197. 